\title{
Tanshinone Production in Roots of Micropropagated Salvia przewalskii Maxim.
}

\section{Ewa Skała* and Halina Wysokińska}

Department of Biology and Pharmaceutical Botany, Medical University of Łódź, Muszyńskiego 1, 90-151 Łódź, Poland. Fax: (48-42) 678-83-48.

E-mail: botanika@pharm.am.lodz.pl

* Author for correspondence and reprint requests

Z. Naturforsch. 60c, 583-586 (2005); received December 29, 2004/February 24, 2005

Production of tanshinones (tanshinone I and IIA) was determined in roots of Salvia przewalskii micropropagated plants. It was found that the total tanshinone content (tashinone I and tashinone IIA) was dependent on the age of the analyzed plants. The roots of 2-year-old in vitro regenerated plants at flowering stage produced highest tanshinone levels $(3.8 \mathrm{mg} / \mathrm{g}$ dry weight of tanshinone I and $7.6 \mathrm{mg} / \mathrm{g}$ dry weight of tanshinone IIA).

Key words: Salvia przewalskii, Tanshinone I and Tanshinone IIA

\section{Introduction}

Salvia przewalskii Maxim. is a herbaceous perennial plant endemic to north-western China ( $\mathrm{Li}$ et al., 1991). The dried roots of this species are used as a drug under the name "Hong Qin Jiao" in the traditional Chinese and Japanese medicine for the treatment of disorders caused by poor blood supply, such as coronary artery disease (Wang et al., 1988). The roots of this plant have been used as a substitute for Salvia miltiorrhiza roots. It has been reported that the main chemical components of $S$. przewalskii roots are abietanetype diterpene pigments - tanshinones, namely cryptotanshinone, tanshinone I, IIA, IIB, przewalskin, przewaquinone A (Li et al., 1991; Xue et al., 2000). The tanshinones isolated also from $S$. miltiorrhiza roots have demonstrated antidermatophytic, anti-inflammatory, antioxidant, antimutagenic and antiplatelet aggregation activities (Chang et al., 1990; Ryu et al., 1997a, b). The antiproliferative activity of tanshinones against different human tumor cells has been shown. Tanshinones have also exhibited cardiovascular effects and are used in the treatment of some coronary heart diseases. They have demonstrated inhibitory activity against Mycobacterium tuberculosis (Baricevic and Bartol, 2000). Tanshinone I and cryptotanshinone prevent the complications of myocardial ischemia (Chen et al., 1997). Furthermore, cryptotanshinone and tanshinone IIB are reported to have bacteriostatic activity against Staphylococcus aureus (Dweck, 2000). Apart from tanshinones also other bioactive compounds have been found in roots of $S$. przewalskii. They include triterpe- noids (przewanoic acid A and B, oleanolic acid and ursolic acid) (Wang et al., 1988) and phenolic derivatives (three lithospermic acid B esters) (Zhijun et al., 1999).

The aim of this study was to determine for the first time the production of tanshinone I and IIA (Fig. 1) in roots of micropropagated plants of Salvia przewalskii.

\section{Experimental}

\section{Establishment of Salvia przewalskii plants}

Plants of Salvia przewalskii were initiated from shoot tips obtained from 4-week-old seedlings and cultured on Murashige and Skoog (MS) (Murashige and Skoog, 1962) basal medium solidified with $0.7 \%$ agar containing $0.5 \mathrm{mg} / 1$ indole-3-acetic acid (IAA) and $1 \mathrm{mg} / 1$ 6-benzylaminopurine (BA). The cultures were kept under light (continuous cool-white fluorescent lamps at a PPFD of $40 \mu \mathrm{mol} \mathrm{m}{ }^{-2} \mathrm{~s}^{-1}$ ) at $26 \pm 2{ }^{\circ} \mathrm{C}$.

The shoots raised in vitro with the length over $1 \mathrm{~cm}$ were excised from shoot cultures and transferred into full- or half-strength MS agar medium without growth regulators or supplemented with $0.1 \mathrm{mg} / \mathrm{l}$ indole-3-butyric acid (IBA). The percentage of rooted shoots, the length of shoots and roots and the number of roots per shoot were recorded after 4 weeks (Table I). The rooted shoots were removed from the culture flasks, washed in tap-water to remove traces of agar attached to the roots and transplanted into pots $(10 \mathrm{~cm}$ diameter $)$ containing a sterilized mixture of soil, sand and peat $(4: 3: 3 \mathrm{v} / \mathrm{v} / \mathrm{v})$. The number of plantlets trans- 
ferred into pots was 45. To maintain high humidity, the plantlets were covered with glass caps gradually opened during a 2 weeks period. They were watered with sterile water during the first seven days. The potted plants were grown in the growing chamber at $26^{\circ} \mathrm{C}$ under continuous cool-white fluorescent tubes of $40 \mu \mathrm{mol} \mathrm{m} \mathrm{m}^{-2} \mathrm{~s}^{-1}$. Survival of the rooted plantlets was recorded at 10 weeks. Then, the hardened plants were transferred to field conditions. They were grown to maturity in the Medicinal Plant Garden of the Medical University of Łódź. The species identity was confirmed in our Department based on the data of the Flora of China (Li and Hedge, 1994).

\section{Statistical analysis}

The data were recorded as means \pm standard error. Significant differences between means were assessed by Duncan multiple range test at a $5 \%$ probability level.

\section{Determination of tanshinones}

For quantitative determination of tanshinones, the roots of $S$. przewalskii micropropagated plants were used. The air-dried roots $(250 \mathrm{mg})$ were extracted five times at room temperature for $3 \mathrm{~h}$ with $30 \mathrm{ml}$ of methanol. The extraction was performed in the dark. The combined methanolic extracts were evaporated to dryness under reduced pressure. The residue of methanolic extract $(5 \mathrm{mg}$ of dry weight) was dissolved in acetonitrile/methanol $(2: 1 \mathrm{v} / \mathrm{v})(10 \mathrm{ml})$. The solution was filtered through $0.45 \mu \mathrm{m}$ filters and analyzed by HPLC using a Varian ProStar apparatus coupled to a UV-Vis detector. A Nucleosil C18 $(5 \mu \mathrm{m})$ column $(250 \times$ $4.6 \mathrm{~mm}$ ) was used with two solvent systems: A, $\mathrm{H}_{2} \mathrm{O}$ containing $5 \mathrm{~mm} \mathrm{~K}_{2} \mathrm{PO}_{4}(\mathrm{pH} \mathrm{2.6})$, and $\mathrm{B}$, acetonitrile/methanol $(2: 1 \mathrm{v} / \mathrm{v})$. The elution programme was as follows: 0.0 to $12.5 \mathrm{~min} 70-95 \% \mathrm{~B}$ (linear change); 12.5 to $15.0 \mathrm{~min} 95 \% \mathrm{~B} ; 15.0$ to $16.0 \min 95-70 \% \mathrm{~B} ; 16.0$ to $20.0 \mathrm{~min} 70 \% \mathrm{~B}$. The flow rate was $1.5 \mathrm{ml} \mathrm{min} \mathrm{m}^{-1}$. The absorbance was measured at $270 \mathrm{~nm}$. The identification of tanshinone I and tanshinone IIA was carried out by comparison of the chromatographic peak retention times and UV spectra of the test solution with those of authentic compounds. Using the abovementioned conditions, two tanshinones were identified as tanshinone I and tanshinone IIA (Table II). The quantification of these tanshinones was achieved using calibration curves prepared with pure compounds. The detector response was linear from 0.008 to $0.166 \mathrm{mg}$ of tanshinone I ( $y=$ $1117.88 x-2.4 ; r=0.999)$ and tanshinone IIA $(y=$ $4440.44 x-8.8 ; r=0.999)$. Tanshinone I (TI) and tanshinone IIA (TIIA) standards were purchased from ChromaDex (USA). The content of TI and TIIA was expressed in $\mathrm{mg} / \mathrm{g}$ dry weight. In this paper the sum of two tanshinones (TI and TIIA) was referred to as the total tanshinone content (TT).

\section{Results and Discussion}

The shoots proliferated on MS medium containing $0.5 \mathrm{mg} / \mathrm{l} \mathrm{IAA}$ and $1 \mathrm{mg} / \mathrm{l} \mathrm{BA}$ were rooted within 4 weeks on full- or half-strength MS media alone or in the presence of $0.1 \mathrm{mg} / \mathrm{l}$ IBA (Table I). The maximum rooting percentage $(97 \%)$ and the length of roots $(4.1 \mathrm{~cm})$ were achieved on fullstrength MS medium supplemented with $0.1 \mathrm{mg} / \mathrm{l}$ IBA (Table I). The rooting plantlets could be successfully acclimatized in pots containing a sterilized mixture of soil, sand and peat. About $80 \%$ of the plants survived the transfer to the field and flowered in the next season.

Levels of tanshinone I (TI) and tanshinone IIA (TIIA) (Fig. 1) were measured in roots of micropropagated plants of S. przewalskii by HPLC (Ta-

Table I. Rooting of Salvia przewalskii shoots on MS and $1 / 2$ MS media without growth regulators or supplemented with auxin (IBA, indole-3-butyric acid) after 4 weeks of culture.

\begin{tabular}{lccccc}
\hline Medium & $\begin{array}{c}\text { Number } \\
\text { of } \\
\text { explants }\end{array}$ & $\begin{array}{c}\text { Shoots of } \\
\text { rooting } \\
(\%)\end{array}$ & $\begin{array}{c}\text { Mean number of } \\
\text { roots/shoot } \\
\pm \mathrm{SE}\end{array}$ & $\begin{array}{c}\text { Mean root length } \\
\pm \text { SE [cm] }\end{array}$ & $\begin{array}{c}\text { Mean shoot length } \\
\pm \mathrm{SE}[\mathrm{cm}]\end{array}$ \\
\hline MS & 30 & 86.7 & $2.31 \pm 0.17^{\mathrm{a}}$ & $3.21 \pm 0.13^{\mathrm{a}}$ & $3.57 \pm 0.10^{\mathrm{a}}$ \\
$1 / 2 \mathrm{MS}$ & 30 & 43 & $2.9 \pm 0.04^{\mathrm{a}}$ & $3.57 \pm 0.13 \mathrm{ac}$ & $1.34 \pm 0.07^{\mathrm{b}}$ \\
MS + IBA 0.1 mg/l & 29 & 96.5 & $2.86 \pm 0.14^{\mathrm{a}}$ & $4.13 \pm 0.11^{\mathrm{bc}}$ & $2.56 \pm 0.16^{\mathrm{c}}$ \\
$1 / 2 \mathrm{MS}+$ IBA 0.1 mg/l & 33 & 75.8 & $2.64 \pm 0.31^{\mathrm{a}}$ & $3.45 \pm 0.03^{\mathrm{a}}$ & $1.35 \pm 0.04^{\mathrm{bd}}$ \\
\hline
\end{tabular}

Means followed by the same letters are not significantly different $(p \leq 0.05)$ using Duncan multiple range test. 
<smiles>Cc1cccc2c3c(ccc12)-c1occc1C3=O</smiles>

Tanshinone I

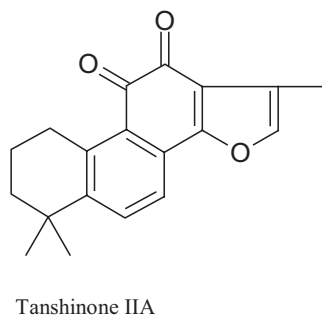

Tanshinone IIA

Fig. 1. Structures of tanshinone I and IIA.

Table II. Separation of tanshinones in methanolic extract obtained from the roots of Salvia przewalskii micropropagated plants by HPLC method. Conditions are described in the section Experimental.

\begin{tabular}{lc}
\hline Compound & Retention times [min] \\
\hline Tanshinone I & 8.013 \\
Tanshinone IIA & 9.620 \\
\hline
\end{tabular}

ble II). It was found that the total tanshinone content (TI and TIIA) varied from 2.7 to $11.4 \mathrm{mg} /$ $\mathrm{g}$ on a dry weight basis. The roots of 2-year-old in vitro regenerated plants grown in the field and harvested at the flowering stage, produced the highest tanshinone levels, namely $3.8 \mathrm{mg} / \mathrm{g}$ dry weight of TI and $7.6 \mathrm{mg} / \mathrm{g}$ dry weight of TIIA. The contents found were twice higher in comparison with the roots of one-year-old micropropagated plants which contained $1.8 \mathrm{mg} / \mathrm{g}$ dry weight of TI and $3.2 \mathrm{mg} / \mathrm{g}$ dry weight of TIIA (Table III). The lowest level of both TI and TIIA was found in roots of 10-week-old in vitro regenerated plants of $S$. przewalskii grown in pots. These differences in tanshinone production could be due to differences in the age and development stage between potted and field-grown plants. When the plants were grown in the field a 3 -fold increase in the average leaf number (53 leaves/plant), a 2-fold increase in

the size of leaves $(29 \mathrm{~cm})$ and root length $(14 \mathrm{~cm})$ as well as its diameter (about $5 \mathrm{~mm}$ ) were noted. The surface of the roots showed a red color which suggests that tanshinones are localized mainly in the periderm and cortex layer.

TI and TIIA have been previously isolated from roots of $S$. przewalskii, but this is the first report showing the quantitative analysis of the tanshinones in the species. So far such studies have been restricted to in vitro cultures and roots of Salvia miltiorrhiza (Okamura et al., 1991; Hu and Alferman, 1993). For example studies carried out by Okamura etal. (1991) showed that the TI and TIIA content estimated in roots of one-year-old regenerated plants and roots of parent plants of S. miltiorrhiza was $1.27 \%$ and $1.67 \%$ on a dry weight basis, respectively. The values were comparable with these found by us in roots of regenerated plants of $S$. przewalskii although relative proportions between TI and TIIA in S. przewalskii and $S$. miltiorrhiza roots were different. The results are of particular interest since roots of $S$. miltiorrhiza are the most important source of tanshinones. The present study showed that also roots of S. przewalskii provide a suitable material for a high production of tanshinones, particularly that of TIIA. The compound such as sodium tanshinone IIA sulfonate (STS) has shown a sufficient promise to be used in clinical trials for treatment of patients with cardiovascular diseases and cerebral thromboembolism symptoms (Baricevic and Bartol, 2000).

\section{Acknowledgements}

We would like to thank Professor Wojciech Mielicki (Department of Pharmaceutical Biochemistry, Medical University of Łódź) for his analysis of HPLC. This work was supported by the State Committee for Scientific Research [No. 502-13-842 (189) and grant No. 2092/P05/2003].

Table III. Content of tanshinones in roots of in vitro regenerated plants of Salvia przewalskii.

\begin{tabular}{lccc}
\hline Material & \multicolumn{2}{c}{$\begin{array}{c}\text { Content } \\
\text { Tanshinone I }\end{array}$} & Total \\
\hline Roots of 10-week-old plants ${ }^{\mathrm{b}}$ & $1.999 \pm 0.180$ & $0.687 \pm 0.162$ & $2.686 \pm 0.330$ \\
Roots of one-year-old plants $^{\mathrm{c}}$ & $3.231 \pm 0.299$ & $1.758 \pm 0.197$ & $4.989 \pm 0.349$ \\
Roots of two-year-old plants $^{\mathrm{d}}$ & $7.588 \pm 0.336$ & $3.780 \pm 0.241$ & $11.368 \pm 0.453$ \\
\hline
\end{tabular}

\footnotetext{
a Results are means \pm standard error from three independent experiments

b Cultured in the pots.

c Cultured in the field since May 2003 and harvested in September 2003.

d Cultured in the field since May 2003 and harvested in July 2004.
} 
Baricevic D. and Bartol T. (2000), Pharmacology. The biological/pharmacological activity of the Salvia genus. In: Sage: the Genus Salvia (Kintzios S. E., ed.). Harwood Academic Publishers, Amsterdam, pp. 143-184.

Chang H. M., Cheng K. P., Choang T. F., Chow H. F., Chui K. Y., Hon P. M., Tan F. W. L., Yang Y., and Zhong Z. P. (1990), Structure elucidation and total synthesis of new tanshinones isolated from Salvia miltiorrhiza Bunge (Danshen). J. Org. Chem. 55, 3537-3543.

Chen H., Yuan J.-P., Chen F., Zhang Y.-L., and Song J.-Y. (1997), Tanshinone production in Ti-transformed Salvia miltiorrhiza cell suspension cultures. J. Biotechnol. 58, 147-156.

Dweck A. C. (2000), Introduction. The folklore and cosmetic use of various Salvia species. In: Sage: the Genus Salvia (Kintzios S. E., ed.). Harwood Academic Publishers, Amsterdam, pp. 1-25.

Hu Z. B. and Alferman A. W. (1993), Diterpenoid production in hairy root cultures of Salvia miltiorrhiza. Phytochemistry 32, 699-703.

Li X.-W. and Hedge I. C. (1994), Salvia L. Flora of China 17, 195-201.

Li B., Niu F.-D., Lin Z.-W., Zhang H.-J., Wang D.-Z., and Sun H.-D. (1991), Diterpenoids from the roots of Salvia przewalskii. Phytochemistry 30, 3815-3817.
Murashige T. and Skoog F. (1962), A revised medium for rapid growth and bioassays with tobacco tissue cultures. Physiol. Plant. 15, 473-497.

Okamura N., Kobayashi K., Yagi A., Kitazawa T., and Shimomura K. (1991), High-performance liquid chromatography of abietane-type compounds. J. Chromatogr. 542, 317-326.

Ryu S. Y., Lee C. O., and Choi S. U. (1997a), In vitro cytotoxicity of tanshinones from Salvia miltiorrhiza. Planta Med. 63, 339-342.

Ryu S. Y., No Z., Kim S. H., and Ahn J. W. (1997b), Two novel abietane diterpenes from Salvia miltiorrhiza. Planta Med. 63, 44-46.

Wang N., Niwa M., and Luo H.-W. (1988), Triterpenoids from Salvia przewalskii. Phytochemistry 27, 299-301.

Xue M., Shi Y., Cui Y., Zhang B., Luo Y., Zhou Z., Xia W., Zhao R., and Wang H. (2000), Chemical constituents from Salvia przewalskii Maxim. Tianran Chanwu Yanjiu Yu Kaifa 12, 27-32 (Chemical Abstracts 135, 31224).

Zhijun W., Mingan O., and Chongren Y. (1999), Polyphenolic constituents of Salvia przewalskii. Yunnan Zhiwu Yahjiu 21, 512-516 (Chemical Abstracts 132, 332013). 